\title{
PRODUTIVIDADE E QUALIDADE DE FRUTOS DE PROGÊNIES DE MARACUJAZEIRO-AZEDO CULTIVADOS NO DISTRITO FEDERAL ${ }^{1}$
}

\author{
KARULINY DAS GRAÇAS COIMBRA², JOSÉ RICARDO PEIXOTO², \\ MARCELO ALVES DE FIGUEIREDO DE SOUSA ${ }^{2}$, NILTON TADEU VILELA JUNQUEIRA ${ }^{3}$
}

RESUMO - Este trabalho teve como objetivo avaliar a produtividade e a qualidade de frutos de progênies de maracujazeiro-azedo cultivados no Distrito Federal. Foi conduzido na Fazenda Água Limpa-UnB, utilizando-se de delineamento de blocos casualizados, com 14 tratamentos (progênies), 04 repetições, sendo a parcela útil de oito plantas. As progênies avaliadas foram: Vermelhão Ingaí, EC-RAM, AR01, AR02, mar20\#36, mar20\#46, AP1, FP01, FB200, RC3, GA2-A1*AG, mar20\#03, mar20\#23 e mar20\#09. As características analisadas em 75 colheitas foram: produtividade $(\mathrm{kg} / \mathrm{ha})$, massa média de frutos $(\mathrm{g})$, número de frutos por hectare, coloração da casca e classificação quanto ao tamanho. Houve maior rendimento em Vermelhão Ingaí, EC-RAM e AR01. O Vermelhão Ingaí produziu a maior quantidade de frutos por hectare, estatisticamente superior aos demais. O EC-RAM obteve o maior número de frutos rosa e roxo. Todas as progênies apresentaram maior produção de frutos de cor amarela. O peso médio total variou de $83 \mathrm{~g}$ em mar20\#36 e $128 \mathrm{~g}$ em EC-RAM. A maior produtividade de frutos para fins industriais foi verificado em Vermelhão Ingaí com frutos de primeira e mar20\#46 com frutos 1B. Já para consumo in natura foi observado em AR02 com frutos 1A e 2 A e em AR01 com frutos 3 A.

Termos para indexação: Passiflora edulis, Produção, Cultivo em campo, Fitotecnia.

\section{PRODUCTIVITY AND QUALITY OF FRUITS OF 14 PROGENIES OF YELLOW PASSION FRUIT CULTIVATED IN FEDERAL DISTRIC}

\begin{abstract}
This study was carried out in order to evaluate the yield of 14 progenies of yellow passion fruit grown in Federal District, Brazil. It was conducted at the Água Limpa Farm - University of Brasilia using a randomized block design with 14 treatments (progenies), 04 replications, and plots consisting of eight plants. The progenies were: Vermelhão Ingaí, EC-RAM, AR01, AR02, mar20\#36, mar20\#46, AP1, FP01, FB200, RC3, GA2-AR1*AG, mar20\#03, mar20\#23 and mar20\#09. The parameters analyzed after 75 harvests were: productivity $(\mathrm{Kg} / \mathrm{ha})$, average fruit weight $(\mathrm{g})$, number of fruits per hectare; peel color and classification by size. The highest yields were obtained for the progenies Vermelhão Ingaí, EC-RAM and AR01. Among them, Vermelhão Ingaí produced the highest number of fruits. EC-RAM produced the largest number of pink and purple fruits. All progenies showed a higher yield of yellow fruits. The total average weight ranged from $83 \mathrm{~g}$ in mar20\#36 and $128 \mathrm{~g}$ in EC-RAM. The highest yield of fruits for industrial use was found in Vermelhão Ingaí with first class fruits and mar20\#46 with 1B fruits. The greater producer of fruits for fresh consumption was AR02 with 1A and 2A fruits and AR01 with 3A fruits.
\end{abstract}

Index terms: Passiflora edulis, Production, Cultivation Field, Crop Science.

1'(Trabalho 002-12). Recebido em: 02-01-2012. Aceito para publicação em: 05-09-2012. Extraído da dissertação de mestrado apresentada pelo primeiro autor à Universidade de Brasília (UnB), Brasília-DF. Financiado pelo CNPq.

${ }^{2} E_{n g}$. Agr ${ }^{a}$. M.SC. e Eng. Agr. Dr. Faculdade de Agronomia e Veterinária, Universidade de Brasília, Campus Universitário Darcy Ribeiro, C.P. : 04508; CEP 70.910-970 Brasília, DF. E-mails: karol.agro@hotmail.com, peixoto@unb.br, marcelosousa@unb.br ${ }^{3}$ Eng. Agr. Dr. Embrapa - Centro de Pesquisa Agropecuária dos Cerrados, Caixa Postal 08223, CEP 73301-970 Planaltina, DF. E-mail: junqueir@cpac.embrapa.br 


\section{INTRODUÇÃO}

O maracujazeiro apresenta alta variabilidade, grandes diferenças na capacidade produtiva e, principalmente, variação nas características dos frutos além de resistência a patógenos. A caracterização dessa variabilidade genética é a base do sucesso dos trabalhos de seleção e melhoramento genético, sendo uma importante demanda para a pesquisa (FALEIRO et al., 2008).

A grande variabilidade dos frutos ainda está presente nos pomares comerciais porque a maioria dos produtores não utiliza cultivares com um padrão homogêneo nas características do fruto, altamente produtivas e capazes de atender aos mercados mais exigentes. Neste caso, faz-se necessário classificar os frutos após a colheita, selecionando-os por tamanho e cor, com diferenças bastante significativas nos preços alcançados para cada uma das categorias. $\mathrm{O}$ peso dos frutos é uma das características a serem melhoradas, cuja seleção pode contribuir para um rápido incremento à produtividade da cultura.

O Brasil é o maior produtor do maracujá-azedo, com crescente demanda por esta fruta, tanto para o mercado de suco processado, quanto para o da fruta in natura (COSTA et al., 2008). O crescimento da produção e da comercialização de maracujá indica que existe demanda para o consumo tanto no mercado interno como para exportação.

Embora o Brasil seja o maior produtor, a produtividade média brasileira de maracujá-azedo está em torno de 14 t/ha/ano, sendo considerada relativamente baixa, pois ações de pesquisa e desenvolvimento com progênies-elite já alcançaram 50 t/ha/ ano (FALEIRO et al., 2008). A baixa produtividade é citada por diversos autores como um dos principais problemas da cultura, destacando a necessidade de pesquisas para o desenvolvimento de variedades melhoradas e para melhor definir tecnologias de produção, capazes de proporcionar o aumento da produtividade, a possibilidade do aumento na sobrevida da cultura e a melhoria da qualidade dos frutos, que são essenciais para o sucesso do agricultor.

Dessa forma, a seleção e o desenvolvimento de cultivares de maracujazeiro- azedo que apresentem boa produtividade e qualidade de seus frutos são de fundamental importância para o desenvolvimento da cultura no País. Nesse contexto, objetivou-se, no trabalho, a avaliação de 14 progênies e acessos-elite de maracujazeiro-azedo quanto ao desempenho agronômico nos aspectos de produtividade estimada ( $\mathrm{kg} / \mathrm{ha})$, massa média dos frutos (g); classificação dos frutos em cinco classes, de acordo com o diâmetro equatorial, número de frutos por hectare e coloração da casca (amarelo, rosa ou roxo), visando a uma possível seleção para futuros programas de melhoramento genético de maracujazeiro-azedo.

\section{MATERIAL E MÉTODOS}

O experimento foi realizado na Fazenda Água Limpa, situada em Vargem Bonita, distante $25 \mathrm{~km}$ ao sul do Distrito Federal, e pertencente à Universidade de Brasília (UnB), com uma latitude de $15^{\circ} 56^{\prime} \mathrm{Sul}$, longitude de $47^{\circ} 56^{\prime}$ Oeste e $1.100 \mathrm{~m}$ de altitude. O clima da região é do tipo $\mathrm{AW}$, caracterizado por chuvas concentradas no verão, de outubro a abril, e invernos secos, de maio a setembro. O experimento foi conduzido em solo do tipo Latossolo Vermelho-Amarelo, fase argilosa, profundo, com boa drenagem e baixa fertilidade natural. A análise de solo apresentou os seguintes resultados: $\mathrm{Al}(0,05 \mathrm{meq}) ; \mathrm{Ca}+\mathrm{Mg}(1,9$ meq); P (4,5 ppm); K (46 ppm); pH (água) 5,4; $\mathrm{MO}$ $43,7 \mathrm{~g} / \mathrm{kg}$, saturação de Al 4\% e V 16\%. Foi realizada calagem na área e incorporado $1 \mathrm{~kg}$ de superfosfato simples por cova.

Utilizou-se o delineamento de blocos casualizados, em esquema simples, com 14 tratamentos (progênies), quatro repetições, com 8 plantas úteis por parcela. As progênies e acessos-elite avaliados foram: mar20\#23, FB200, mar20\#03, mar20\#09, AR01, AR02, mar20\#36, FP01, GA2-AR1*AG, mar20\#46, EC-RAM, Vermelhão Ingaí, RC3 e AP1. A procedência de tais materiais se encontra na Tabela 1.

As mudas foram obtidas em casa de vegetação, por meio de semeadura realizada em 10 de junho de 2006, em sacos plásticos com 1L de capacidade, contendo terra peneirada. O transplante para o campo realizou-se em 20 de setembro de 2006. Utilizou-se o espaçamento $3 \times 3$ metros, totalizando 448 plantas, numa área de $4.032 \mathrm{~m}^{2}$.

O pomar foi conduzido utilizando o sistema de sustentação de espaldeira vertical, com mourões distanciados por 6 metros e dois fios de arame liso a 2,0 e 1,50 m de altura em relação ao solo, respectivamente. As plantas foram conduzidas em haste única, tutoradas por barbante, até o arame, deixando para o fio de arame duas brotações laterais em sentido contrário entre si. As brotações, a partir daí, cresceram livremente, sem podas de renovação. Foi feita irrigação suplementar por gotejamento, realizando 7 horas de irrigação e um turno de rega de dois dias. A média de aplicação de água foi de 1,8 litro por metro linear por hora. O controle de plantas espontâneas foi realizado com roçadeiras, de acordo com a necessidade. As adubações foram realizadas 
de uma maneira geral a cada 15 dias, sendo utilizadas adubações de cobertura em círculo, à distância de 40 $\mathrm{cm}$ a $50 \mathrm{~cm}$ do colo da planta, superficialmente, além de adubação foliar de micronutrientes e fertirrigação de acordo com a necessidade da cultura, segundo recomendações técnicas de Borges et al. (2002).

As avaliações de desempenho agronômico foram realizadas de abril de 2007 a janeiro de 2010, totalizando 75 colheitas em dois anos e nove meses. As colheitas foram realizadas semanalmente, no período de produção, e quinzenalmente, na entressafra, recolhendo-se somente os frutos que se encontravam no chão, ou seja, a partir de sua maturação total. A colheita de cada parcela ( 8 plantas) era realizada separadamente, alocando-se os frutos em caixas devidamente identificadas, de acordo com o croqui da área experimental, e posteriormente eram levadas a um galpão onde se procediam as avaliações. As variáveis estudadas foram: produtividade estimada ( $\mathrm{kg} /$ ha), número de frutos por hectare, massa média dos frutos $(\mathrm{g})$, classificação dos frutos quanto ao diâmetro equatorial (mm), em cinco categorias: primeira $(>55)$, frutos $1 \mathrm{~B}(\leq 55$ até 65$)$, frutos $1 \mathrm{~A}(\leq 65$ até 75$)$, frutos $2 \mathrm{~A}(\leq 75$ até 90$)$ e frutos 3A (<90) (MELETTI 1999 citado por RANGEL, 2002); e classificação dos frutos quanto à coloração em: amarela, rosa e roxa. Não foi feita polinização manual.

As análises de variância de cada característica, bem como a comparação das médias através do teste de Duncan, ao nível de 5\% de significância, foram executadas com o auxílio do "software SANEST" (ZONTA; MACHADO, 1995). Para as variáveis número de frutos rosa e roxo, produtividade rosa e roxo, número de frutos de $2 \mathrm{~A}, 3 \mathrm{~A}$ e produtividade de frutos $3^{\mathrm{a}}$, foi feita a transformação para raiz $(\mathrm{x}+10)$; e para as variáveis: número total de frutos rosa $\mathrm{e}$ roxo, produtividade total estimada de frutos rosa e roxo e número de frutos de primeira para $\log (\mathrm{x}+1)$, garantindo a homogeneidade de variâncias e outras exigências para a aplicação dos testes de significância.

\section{RESULTADOS E DISCUSSÃO}

Houve diferença estatística quanto à produtividade total estimada, número total de frutos, produtividade e número de frutos entre cores e entre número de frutos de primeira, 1B, 1A, 2A e $3 \mathrm{~A}$ entre as progênies.

A produtividade máxima estimada foi em Vermelhão Ingaí, seguida de EC-RAM e AR01, e a mínima em RC3, seguida de AP1 e AR02. Essas progênies diferiram daquelas, estatisticamente, ao nível de significância de 5\%, pelo teste de Duncan (Tabela 2).
O desempenho superior do Vermelho Ingaí também foi verificado por Maia (2008) que analisou a produtividade dos 14 materiais em 2007, verificando que o Vermelhão Ingaí, com $15.700 \mathrm{~kg} / \mathrm{ha}$, foi o único que esteve acima da média nacional, que é de $14.000 \mathrm{~kg} / \mathrm{ha}$. Os dados obtidos no trabalho são corroborados pelos obtidos por Mello (2009) em 2008. Este autor verificou que Vermelhão Ingaí obteve a maior produtividade média, $43.266 \mathrm{~kg} / \mathrm{ha}$, seguida do EC-RAM com $40.673 \mathrm{~kg} / \mathrm{ha}$ e AR01 com 40.603 $\mathrm{kg} / \mathrm{ha}$. A menor produtividade média foi do RC3 com $25.325 \mathrm{~kg} / \mathrm{ha}$. A produtividade total do RC3 chegou a $27.668 \mathrm{~kg} / \mathrm{ha}$.

A maior produção de frutos por hectare foi obtida pelo Vermelhão Ingaí, e a menor por RC3 (Tabela 3). Pode-se observar grande variação na produção de frutos por hectare, o que reflete as diferenças estatísticas entre as várias progênies e acessos-elite avaliados. A superioridade do Vermelhão Ingaí,em termos de número de frutos por hectare, também foi verificada por Maia (2008), que obteve em Vermelhão Ingaí o maior número de frutos produzidos, 142.791 frutos/ha.

Diferenças estatísticas significativas também foram encontradas na produtividade e no número de frutos, nas diferentes colorações de casca e nas categorias quanto ao tamanho.

A maior produtividade e produção de frutos amarelos foram verificadas na progênie Vermelhão Ingaí, e em ECRAM para frutos de coloração rosa e roxa, o que pode ser explicado pela procedência dessas progênies, sendo EC-RAM descendente de plantas de maracujá-roxo e Vermelhão Ingaí do cruzamento com maracujá-amarelo.

As progênies Vermelhão Ingaí e EC-RAM destacaram-se quanto à produtividade e número de frutos com maior interesse industrial (primeira e 1B), diferenciando-se estatisticamente das demais. Já para frutos de comercialização in natura (1A, 2A, $3 \mathrm{~A}$ ), as progênies AR01 e mar20\#09 apresentaram as maiores produções, tanto em termos de produtividade, quanto em produção de número de frutos (Tabelas 2 e 3). Sampaio et al. (2008) tiveram, em dois anos de colheita, maior número de frutos de primeira (industrial) para o acesso AR01, discordando do presente ensaio.

A massa média total variou de $89 \mathrm{~g}$ em Vermelhão Ingaí a $127 \mathrm{~g}$ em AR01. Em frutos amarelos, essa variável foi de $91 \mathrm{~g}$ em Vermelhão Ingaí a 128 $\mathrm{g}$ em AR01 e mar20\#46. Para frutos roxos, variou de 83 g em Vermelhão Ingaí a 144 g em EC-RAM. Para frutos rosas, somente EC-RAM obteve diferença estatística ante as demais progênies (Tabela 4).

Maia et al. (2009), em seu experimento, 
encontraram massa média dos frutos variando de 105 g para o PCF-2 a 192 g para o genótipo AR-01. E número de frutos variando de 33.666 frutos/ha, no genótipo RC 3, a 142.791 frutos/ha, no genótipo PCF-2. Todos os genótipos apresentaram maior produção de frutos amarelos, seguidos de frutos de cor rosa e de cor roxa, corroborando os resultados do presente experimento. Sousa (2005) encontrou, nas progênies mar20\#09, mar20\#03 e FB200, a maior massa média de frutos, sendo $133,50 \mathrm{~g}$ /fruto, $129 \mathrm{~g}$ /fruto e $120,75 \mathrm{~g}$ /fruto, respectivamente.

Vale ressaltar que, durante o período de estabelecimento e produção de frutos, a produtividade foi variável, 1 tendo seu pico no primeiro período de colheita e reduzindo ao longo do tempo. Dentre as possíveis causas, podemse citar as condições físiológicas das plantas e condições ambientais favoráveis à ocorrência de fitopatógenos, aos quais essas progênies não possuem tolerância/resistência. É importante considerar, ainda, a polinização entomófila, que normalmente resulta na produção de frutos menores em relação à polinização manual, em razão do maior número de sementes proporcionado pela polinização manual (JUNQUEIRA et al., 2001). A polinização artificial, que não foi feita neste trabalho, poderia aumentar substancialmente o número de frutos, especialmente aqueles de menor tamanho; porém, provavelmente, reduziria a massa média, o que desfavoreceria a produção destinada ao mercado in natura; mas, por outro lado, seria importante para o mercado industrial que ainda domina o agronegócio do maracujazeiroazedo.

TABELA 1 - Procedências das 14 progênies de maracujazeiro cultivadas no Distrito Federal. FAL-UnB, 2010.

\begin{tabular}{|c|c|}
\hline Progênies & Procedências \\
\hline FB200 & Yellow Master - Cultivar comercial \\
\hline $\mathrm{RC} 3$ & $\begin{array}{l}\text { Híbrido de seleção recorrente (P. edulis } x \text { P. setacea), terceira geração de } \\
\text { retrocruzamento. }\end{array}$ \\
\hline AR02 & $\begin{array}{l}\text { Híbrido oriundo do cruzamento entre duas plantas obtidas de seleção individual de } \\
\text { plantas resistentes à antracnose de uma população da cultivar Roxo Australiano. }\end{array}$ \\
\hline AP1 & $\begin{array}{l}\text { Obtida do cruzamento entre tipos de maracujá-amarelo de alta produtividade, } \\
\text { selecionados em pomar comercial. }\end{array}$ \\
\hline AR01 & $\begin{array}{l}\text { Hibrido }(\mathrm{RC} 1) \text { de polinização controlada entre as cultivares Marília x Roxo } \\
\text { Australiano retrocruzado para Marília, ou seja, F1 x Marília. }\end{array}$ \\
\hline ECRAM & Híbrido entre roxo australiano e amarelo. \\
\hline GA-AR1*AG & Híbrido entre duas plantas obtidas por seleção recorrente. \\
\hline FP01 & $\begin{array}{l}\text { Híbrido entre duas plantas obtidas por seleção individual, com características de } \\
\text { tolerância a fotoperíodos menores. }\end{array}$ \\
\hline Vermelhão Ingaí & P. caerulea $x$ P edulis, geração RC2. \\
\hline $\begin{array}{l}\text { Mar20\#03, } \\
\text { mar20\#09, } \\
\text { mar20\#23, } \\
\text { mar20\#36, } \\
\text { mar20\#46 }\end{array}$ & $\begin{array}{l}\text { Seleção massal de nove genótipos superiores: Maguary mesa 1, Maguary mesa 2, } \\
\text { Havaiano, MSC (Marília Seleção Cerrado), Seleção DF, EC20, F1 (Marília x Roxo } \\
\text { Australiano), F1 (Roxo Fiji x Marília) e RC1 [F1 (Marília x Roxo Australiano) x } \\
\text { Marília (pai recorrente)]. }\end{array}$ \\
\hline
\end{tabular}




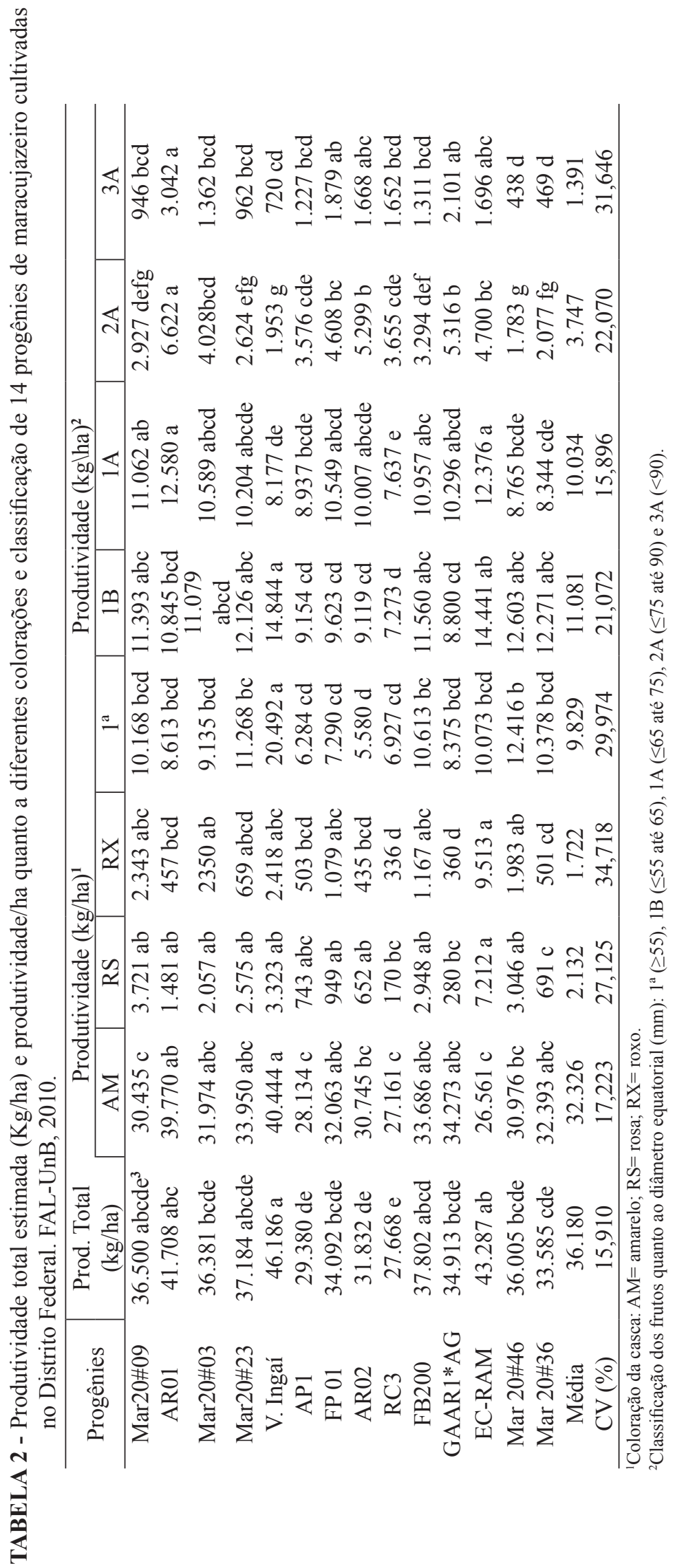




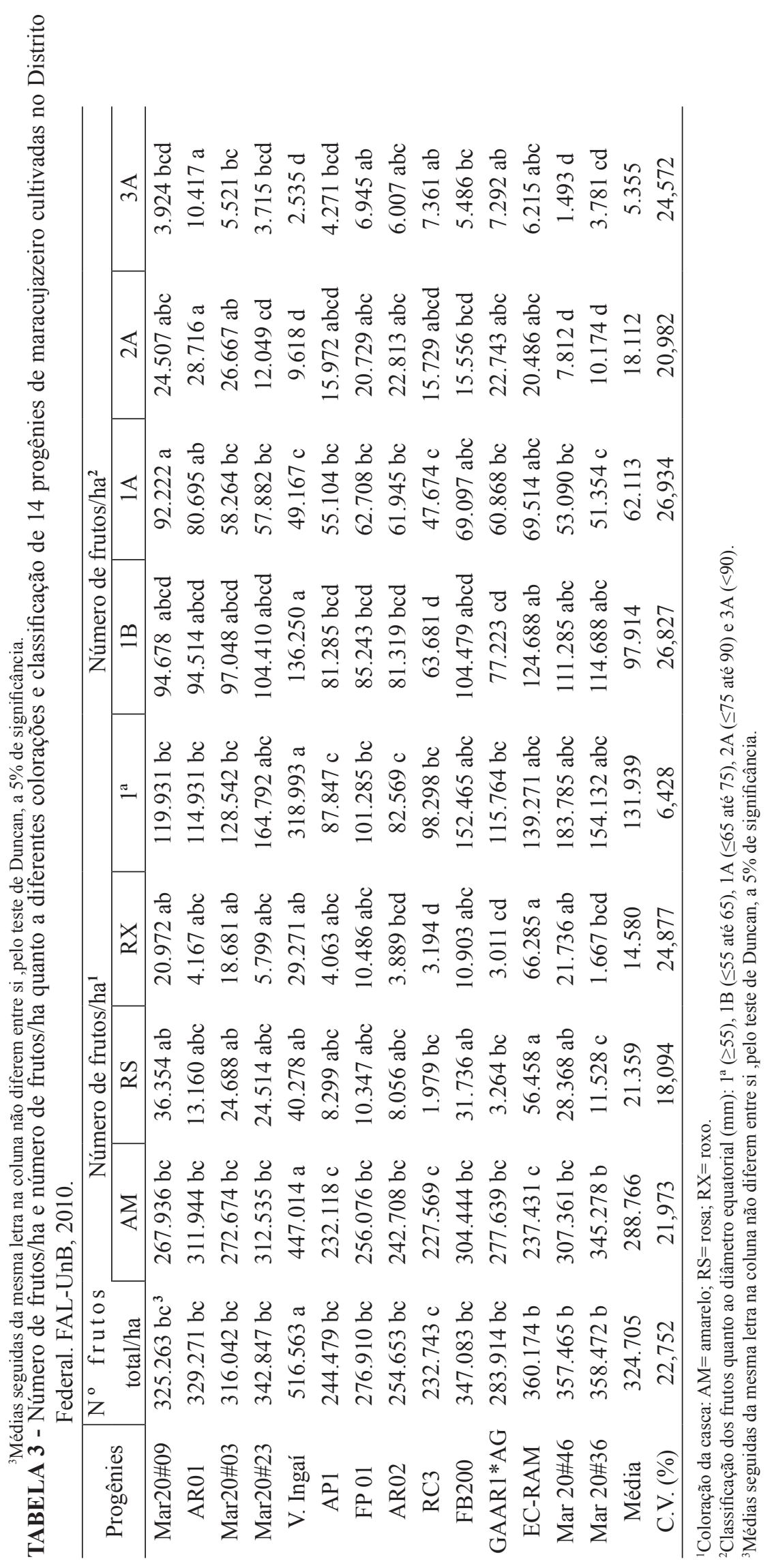


TABELA 4 - Média da massa dos frutos $(\mathrm{Mm})(\mathrm{g})$ e massa média( $\mathrm{Mm})(\mathrm{g})$ de frutos de acordo com a coloração da casca de 14 progênies de maracujazeiro cultivadas no Distrito Federal, FAL-UnB, 2010.

\begin{tabular}{lllll}
\hline \multicolumn{1}{c}{ Progênies } & \multicolumn{1}{c}{ Mm total (g) } & \multicolumn{1}{c}{ Mm amarela (g) } & Mm rosa (g) & Mm roxo (g) \\
\hline Mar 20\#09 & $112 \mathrm{ab}$ & $114 \mathrm{bcd}$ & $102 \mathrm{~b}$ & $112 \mathrm{ab}$ \\
AR01 & $127 \mathrm{a}$ & $128 \mathrm{a}$ & $112 \mathrm{~b}$ & $110 \mathrm{ab}$ \\
Mar 20\#03 & $115 \mathrm{ab}$ & $117 \mathrm{ab}$ & $83 \mathrm{~b}$ & $126 \mathrm{ab}$ \\
Mar 20\#23 & $109 \mathrm{bcd}$ & $109 \mathrm{abc}$ & $105 \mathrm{~b}$ & $114 \mathrm{ab}$ \\
V. Ingaí & $89 \mathrm{~d}$ & $91 \mathrm{~d}$ & $82 \mathrm{~b}$ & $83 \mathrm{~b}$ \\
AP1 & $120 \mathrm{ab}$ & $121 \mathrm{ab}$ & $89 \mathrm{~b}$ & $124 \mathrm{ab}$ \\
FP 01 & $123 \mathrm{ab}$ & $126 \mathrm{ab}$ & $92 \mathrm{~b}$ & $103 \mathrm{ab}$ \\
AR02 & $125 \mathrm{a}$ & $127 \mathrm{a}$ & $81 \mathrm{~b}$ & $112 \mathrm{ab}$ \\
RC3 & $119 \mathrm{ab}$ & $119 \mathrm{ab}$ & $86 \mathrm{~b}$ & $105 \mathrm{ab}$ \\
FB200 & $109 \mathrm{bcd}$ & $111 \mathrm{abs}$ & $93 \mathrm{~b}$ & $107 \mathrm{ab}$ \\
GA2-AR1*AG & $123 \mathrm{ab}$ & $124 \mathrm{ab}$ & $86 \mathrm{~b}$ & $120 \mathrm{ab}$ \\
EC-RAM & $120 \mathrm{ab}$ & $114 \mathrm{bcd}$ & $128 \mathrm{a}$ & $144 \mathrm{a}$ \\
Mar 20\#46 & $101 \mathrm{bcd}$ & $128 \mathrm{a}$ & $107 \mathrm{a}$ & $112 \mathrm{ab}$ \\
Mar 20\#36 & $94 \mathrm{bcd}$ & $117 \mathrm{ab}$ & $60 \mathrm{a}$ & $110 \mathrm{ab}$ \\
Média & 113 & 118 & 93 & 113 \\
CV (\%) & 17,206 & 9,533 & 24,140 & 28,286 \\
\hline
\end{tabular}

Médias seguidas da mesma letra na coluna não diferem entre si, pelo teste de Duncan, a 5\% de significância.

\section{CONCLUSÕES}

1-Os materiais genéticos que apresentam maiores produtividades são o Vermelhão Ingaí, ECRAM e AR01. O Vermelhão Ingaí também produz a maior quantidade de frutos por hectare.

2-A maior produtividade e o maior número de frutos para fins industriais foram verificados em Vermelhão Ingaí e em ECRAM, enquanto para consumo in natura AR01 mostra o melhor desempenho.

3-O EC-RAM merece destaque como o material genético com as maiores percentagens de frutos roxo e rosa.

4-As diferenças de produtividade e de qualidade dos frutos verificadas nas progênies mostram o potencial para seleção e futuros cruzamentos, visando ao aumento de produtividade e de qualidade de frutos.

\section{AGRADECIMENTOS}

Ao Conselho Nacional de Pesquisa, pela concessão da bolsa de estudos.

À Faculdade de Agronomia e Fazenda Água Limpa (UnB), pela oportunidade de execução do trabalho de campo.

Aos funcionários da Fazenda Água Limpa (UnB), Miro, Evangelista e Queen, pelo apoio na condução do experimento.

\section{REFERÊNCIAS}

BORGES, A. L.; RAIJ, B. V.; MAGALHÃES, A. F. J.; BERNARDI, A. C. C.; LIMA, A.A. Nutrição, calagem e adubação mineral do maracujazeiro irrigado. Cruz das Almas: Embrapa Mandioca e Fruticultura, 2002. 8 p. (Circular Técnica, 50).

COSTA, A. de F.S.; COSTA, A.N.; VENTURA, J.A.; FANTON, C.J.; LIMA, I.M.; CAETANO, L.C.S.; SANTANA, E.N. Recomendações técnicas para o cultivo do maracujazeiro. Vitória-Incaper, 2008. 56p. (Documentos, 162). 
FALEIRO, F.G.; JUNQUEIRA, N.T.V.; BRAGA, M.F. Pesquisa e desenvolvimento do maracujá. In: ALBUQUERQUE, A.C.S.; SILVA, R.C. (Ed.). Agricultura tropical: quatro décadas de inovações tecnológicas, institucionais e políticas. Brasília: Embrapa, 2008. p. 411-416

JUNQUEIRA, N.T.V.; VERAS, M.C.M.; NASCIMENTO,A.C.; CHAVES, R.C.; MATOS,A.P.; JUNQUEIRA, K.P. A importância da polinização manual para aumentar a produtividade do maracujazeiro. Planaltina: Embrapa Cerrados, 2001. (Documento, 41).

MAIA, T.E.G.; PEIXOTO, J.R.; JUNQUEIRA, N.T.V.; SOUSA, M.A.F. Desempenho agronômico de genótipos de maracujazeiro-azedo cultivados no Distrito Federal. Revista Brasileira de Fruticultura, Jaboticabal, v.31, n. 2, 2009.

MAIA, T.E.G. Desempenho agronômico e reação à verrugose e à virose do endurecimento dos frutos de genótipos de maracujazeiro-azedo cultivados no Distrito Federal. 2008. 121f. Dissertação (Mestrado em Ciências Agrárias) - Faculdade de Agronomia e Medicina Veterinária, Universidade de Brasília, 2008.

MELLO, R.M. Desempenho agronômico e reação à virose do endurecimento dos Frutos em genótipos de maracujazeiro-azedo, cultivados no Distrito Federal. 2009. 134 f. Dissertação (Mestrado) Faculdade de Agronomia e Medicina Veterinária, Universidade de Brasília, Brasília, 2009.
RANGEL, L.E.P. Desempenho agronômico de nove progênies de maracujazeiro-azedo cultivados sob três níveis de adubação potássica no Distrito Federal. 2002. 45 f. Dissertação (Mestrado) Universidade de Brasília, Brasília, 2002.

SAMPAIO, A.C.; SCUDELLER, N.; FUMIS, T.F.; ALMEIDA, A.M.; PINOTTI, R.N.; GARCIA, M.J.M.; PALLAMIN, M.L. Manejo cultural para o maracujazeiro-azedo em ciclo anual, visando à convivência com o vírus do endurecimento dos frutos: um estudo de caso. Revista Brasileira de Fruticultura, Jaboticabal, v.30, n.2, p. 343-347, 2008.

SOUSA, M.A.F. Avaliação da produtividade, incidência e severidade de doenças em frutos de 17 genótipos de maracujazeiro-amarelo, cultivados no Distrito Federal. 2005. 120f. Dissertação (Mestrado em Ciências Agrárias) - Faculdade de Agronomia e Medicina Veterinária, Universidade de Brasília, Brasília, 2005.

ZONTA, E.P.; MACHADO, A.A. Sistema de análises estatísticas (SANEST) para microcomputadores. In: SIMPÓSIO DE ESTATÍSTICA APLICADA À EXPERIMENTAÇÃO, 1995, Piracicaba. Resumos... Campinas: Fundação Cargill, 1995. p. 17-18. 